Goldschmidt 2021 Abstract

https://doi.org/10.7185/gold2021.5100

\section{Preliminary mineralogical and morphological characterisation of dental alginates on the light of silica health hazard}

\author{
TOMMASO BARONI ${ }^{1}$, PROF. ELENA BELLUSO SR. ${ }^{2}$, \\ SILVANA CAPELLA ${ }^{3}$, GIORDANO MONTEGROSSI ${ }^{4}$, \\ MAURIZIO ROMANELLI ${ }^{1}$, FABIO CAPACCI ${ }^{5}$ AND \\ FRANCESCO DI BENEDETTO ${ }^{6}$
}

${ }^{1}$ University of Florence

2 via Valperga Caluso 35

${ }^{3}$ University of Torino

${ }^{4} \mathrm{CNR}$

${ }^{5}$ Azienda Sanitaria di Firenze

${ }^{6}$ University of Ferrara

Presenting Author: tommaso.baroni@unifi.it

The production and use of dental alginates have been linked to a case of severe silicosis [1], shedding light to a potential underestimated source of exposure to toxicants for workers, in a professional branch where silica-related risk has not been yet considered. In the present study, we sampled two commercial silica-based dental alginates and undertook a thorough mineralogical, microchemical and spectroscopic investigation.

X-ray Powder Diffraction was used to establish the mineralogical composition, in combination with SEM-EDS analysis, in order to assess particle size, morphology and chemistry of the dental alginates components. Finally, preliminary room-temperature EPR investigations were carried out to identify select paramagnetic species, as $\mathrm{Fe}(\mathrm{III})$ and radicals.

The results point to the presence of an extensive amount of diatomaceous earth, clearly identified by micromorphology, primarily formed by cristobalite crystalizing as a result of the high-temperature transformation of amorphous silica during the calcination process to which diatomaceous earth had been subjected. Subordinate amounts of associated phases such as gypsum, talc, magnesium oxide (besides potassium hexafluorotitanate and $\mathrm{Na} / \mathrm{K}$ alginates) and a relevant portion of an amorphous-to-cryptocrystalline silica fraction were also identified. In terms of size distribution, all the different components are represented by particles of different shapes and densities with size $<100 \mu \mathrm{m}$ [2]. While the associated phases do not fall outside the inhalable fraction, the presence of a significant amount of complete diatoms shells with diameter $<$ $10 \mu \mathrm{m}$ and abundant scattered fragments $<4 \mu \mathrm{m}$ sets the cristobalite into the thoracic and respirable fraction categories [2].

Based on the obtained results, we warmly support the reconsideration of dental alginates in terms of the definition of their health risks, mostly consisting of a very harmful silica polymorph, as cristobalite. Interesting parallelisms can be fostered with the well-known epidemiological studies on the cohorts of workers of the diatomaceous earth [3-5].

[1] Barbieri et al. (2020) Med Lav; 111, 3: 222-231

[2] CEN (1993), European Standard, EN481:1993
[3] Legge \& Rosencrantz (1932) Am J Public Health; 22: 1055-1060

[4] Ebina et al. (1952) Tohoku J Exp Med; 56: 214

[5] Paterni (1965) Folia Med (Napoli); 48: 183-188 